\title{
Educação em tempo integral: direito e financiamento
}

\section{Full-time education: law and finance}

\author{
Janaina S. S. Menezes ${ }^{1}$
}

\begin{abstract}
RESUMO
$\mathrm{O}$ artigo tem por objetivo analisar as possibilidades e desafios associados ao financiamento da educação em tempo integral. Parte-se da análise dos mo(vi)mentos legais relacionados à Educação Integral (em tempo) integral presentes na Constituição Federal de 1988 e nas normatizações que se seguiram à sua promulgação, chegando ao Fundeb. Paralelamente são destacadas as políticas, os programas e os dados estatísticos associados ao financiamento da educação em tempo integral. Partindo do entendimento de que a garantia dos direitos sociais e, em especial, a garantia do direito à educação (integral) se faz associar a fontes estáveis e suficientes de recursos, o texto revela que, no período investigado, ocorreram avanços que possibilitam às instâncias subnacionais o desenvolvimento de políticas vinculadas à educação em tempo integral.

Palavras-chave: políticas públicas em educação; Educação Integral; Educação em tempo integral; direito à educação; financiamento da Educação.
\end{abstract}

\begin{abstract}
The article aims to analyze the possibilities and challenges associated with financing of full-time education. It departs from the analysis of legal mo(ve) ments related to comprehensive full-time education present in the Federal Constitution of 1988 and from the norms following the enactment, coming to Fundeb. At the same time, policies, programs and statistics associated with the financing of full-time education are highlighted. Based on the understanding that the guarantee of social rights and in particular the guarantee of the right to (full) education is associated to stable and sufficient sources of funds, the text reveals that, in the investigated period, there
\end{abstract}

1 Doutora em Educação, professora da Universidade Federal do Estado do Rio de Janeiro (Unirio), Brasil. E-mail: janainamenezes@hotmail.com. 
were advances that enable the subnational instances to develop policies related to full-time education.

Keywords: public policies in education; Integral Education; full-time education; right to education; financing of education.

\section{Considerações iniciais}

A educação é: um direito universal; a chave do desenvolvimento humano sustentável; uma responsabilidade do Estado; e alcançável se os governos mobilizarem sua vontade política e recursos disponíveis.

Unesco

Nos últimos anos, o Brasil vem conquistando especial destaque no contexto internacional. Atualmente, o país detém o posto de maior potência econômica na América Latina e está entre aqueles que se destacam no cenário mundial pelo rápido crescimento de suas economias em desenvolvimento, chamados pela sigla BRIC (Brasil, Rússia, Índia e China).

Em meio a este cenário, a educação está sendo chamada a dar respostas, a revelar suas condições para formar os cidadãos que deverão contribuir com a continuidade desse processo de desenvolvimento. Integrante de um contexto de múltiplas variáveis correlacionadas, a educação em tempo integral vem sendo apresentada não apenas como estratégia para o necessário avanço educacional historicamente devido ao país, mas, especialmente, como possibilidade de contribuir para o avanço da aprendizagem dos alunos, bem como com sua formação mais ampla, voltada para seu pleno desenvolvimento. Sob essa perspectiva, a discussão sobre a necessidade de as instâncias subnacionais construírem, cada qual - a partir de um projeto educacional, elaborado coletivamente, que tenha por base suas expectativas e especificidades locais - sua política de educação (em tempo) integral vem conquistando significativo espaço nas arenas educacionais.

Em meio a esse processo de desenvolvimento, permeado por um contexto de competição globalizada, paradoxalmente, algumas perguntas ainda se fazem presentes no país: Como está expresso o direito à Educação Integral e ao tempo integral no ordenamento normativo, especialmente na legislação mais recente? E mais, tendo por base o entendimento de que a garantia desses direitos se faz 
associar a fontes de financiamento, quais são as possibilidades de recursos associados à educação em tempo integral no contexto atual?

Nas próximas seções, este texto se propõe a refletir sobre estas duas questões - direito e financiamento da educação (em tempo) integral -, tendo por referência o entendimento de que esses são apenas dois dos muitos desafios que cada uma das instâncias federadas deve considerar ao se propor a formular sua política de educação (em tempo) integral.

\section{Educação (em tempo) Integral: direito e financiamento}

Diversos autores vêm desenvolvendo estudos sobre o direito à educação, tendo como uma de suas orientações o ordenamento normativo estabelecido a partir da promulgação da Constituição Federal de 1988 (CF 88). Todavia, não são muitos que se detêm sobre a reflexão do direito à educação (em tempo) integral.

A Carta de 1988, alinhada com os valores jurídicos propugnados por documentos que refletem algumas das conquistas do século XX, tais como a Declaração Universal dos Direitos do Homem (1948) e a Convenção Internacional sobre os Direitos da Criança (1989), ordenou, assim como as Constituições que a sucederam, que a educação deve se constituir direito do cidadão, tendo como um de seus pressupostos o fato de a cidadania ser considerada fundamento da República (CF 88, art. $1^{\circ}$, inciso II).

No que tange ao direito à educação, a Constituição Federal de 1988, além de apresentá-lo como o primeiro direito social (art. $6^{\circ}$ ), explicita que, na condição de "direito de todos e dever do Estado e da família", visa o "pleno desenvolvimento da pessoa, seu preparo para o exercício da cidadania e sua qualificação para o trabalho" (art. 205), conduzindo à compreensão de que esse direito está associado a uma Educação Integral. Nesse sentido, observa-se que, segundo Rios (2006), a expressão "Educação Integral" constitui-se pleonasmo, pois “ou a educação é integral ou ela não pode ser chamada de educação" (p. 52), reflexão esta que vai ao encontro do fato de a Carta de 1988 não fazer menção direta a essa expressão.

O texto constitucional determina ainda que o Estado deve garantir a todos "o pleno exercício dos seus direitos culturais e acesso às fontes da cultura nacional" (art. 215), bem como valorização da diversidade étnica e regional. Sob essa perspectiva, a análise da conjunção do ordenamento constitucional até aqui referido possibilita o entendimento de que a Educação Integral constitui-se direito de todos - e de cada um, haja vista a diversidade ser considerada característica primordial e valorativa dos tecidos social e cultural de países. 
Por sua vez, as principais normatizações associadas à educação que se seguiram à Constituição de 1988 - Estatuto da Criança e do Adolescente, Lei $n^{\circ}$ 8.069/1990 (ECA); Lei de Diretrizes e Bases da Educação Nacional, Lei n ${ }^{\circ}$ 9.394/1996 (LDB); Plano Nacional de Educação, Lei 10.172/2001 (PNE, 20012010) - foram unânimes em reiterar o direito à educação (integral).

Embora o conceito de Educação Integral esteja em constante movimento, pode-se afirmar que, no contexto atual, entre outros aspectos, é considerado ação estratégica voltada para a garantia da atenção e do desenvolvimento integral de crianças e jovens. A este respeito é importante destacar que o Estatuto da Criança e do Adolescente traz à tona reflexões que envolvem a relação entre proteção social e Educação Integral. Para Faria (2010), muitas são as discussões que apresentam a proteção social como um dos pilares da Educação Integral. Segundo a autora:

As desigualdades socioeconômicas que geram pobreza e exclusão, próprias da sociedade capitalista, engendram a falta de proteção social. Dessa forma, a proteção social deve ser parte fundamental da implantação da Educação Integral para que haja garantia de vida digna e inclusão social sem as quais não haverá condições para o exercício da cidadania (p. 32).

A LDB e o PNE 2001-2010, conforme já evidenciado, reiteram o direito à Educação Integral, e, de forma não inter-relacionada, trazem para a reflexão o tempo integral, um dos possíveis alicerces para a construção dessa educação. Se por um lado a LDB associa o tempo integral exclusivamente ao ensino fundamental (art. 34, $\S 2^{\circ}$ ), por outro o PNE 2001-2010, com algumas restrições, vincula-o também à educação infantil (MENEZES, 2009). Todavia, nenhuma dessas duas legislações definiu claramente o que seja tempo integral ${ }^{2}$. Essa lacuna legal, embora não desejável no que tange à garantia do direito à educação em tempo integral, provavelmente redundou em pelo menos um efeito positivo: a lei, ao não definir, estimulou a discussão entre os profissionais da educação sobre as contribuições, desafios e impactos do tempo integral no processo de formação dos alunos, além de fortalecer o debate sobre a relação entre educação integral e tempo integral, construindo assim, entre outros, subsídios a serem incorporados nas normatizações que se sucederam.

2 O PNE 2001-2010 esboçou uma definição inicial para o tempo integral, todavia a forma ampla como foi apresentada - "[...] expandir a escola de tempo integral, que abranja um período de pelo menos sete horas diárias" (Meta 21/Ensino Fundamental) - possibilita diferentes e diversas interpretações. 
Nesse sentido, pode-se considerar que o Fundo de Manutenção e Desenvolvimento da Educação Básica e de Valorização dos Profissionais da Educação $(\text { Fundeb })^{3}$ constituiu-se como divisor de águas no que tange à garantia do direito à educação em tempo integral. O Fundo avançou em relação às leis anteriormente mencionadas (LDB e PNE), entre outros aspectos, por associar o tempo integral a todas as etapas da educação básica (educação infantil, ensino fundamental e ensino médio). Além disso, o Fundeb também se destacou em relação ao Fundo que lhe antecedeu, o Fundef ${ }^{4}$, por destinar recursos não apenas para o ensino fundamental, mas para as diferentes etapas, modalidades e tipos de estabelecimento de ensino da educação básica, incluindo, ineditamente, recursos para as matrículas em tempo integral.

Sob essa perspectiva, com vistas à distribuição dos recursos do Fundeb, necessário se fez com que, no âmbito desse Fundo, fosse delimitado o conceito de educação básica em tempo integral, uma vez que vinham, e continuam sendo, desenvolvidas no país, por vezes sob a responsabilidade de uma mesma esfera administrativa, experiências de educação em jornada ampliada com diferentes extensões de carga horária. Enfim, era necessário, entre outros aspectos, estabelecer um limite mínimo de tempo associado à jornada escolar, a fim de que os governos municipais e estaduais pudessem fazer jus ao recebimento de recursos relacionados ao empenho vinculado à implantação, manutenção e estímulo ao aumento das matrículas com tempo integral sob sua responsabilidade. Apresentadas essas considerações, para fins de destinação de recursos do Fundeb, o Decreto $n^{\circ}$ 6.253/2007 regulamentou a educação básica em tempo integral como sendo a "jornada escolar com $d u$ ração igual ou superior a sete horas diárias, durante todo o periodo letivo, compreendendo o tempo total que um mesmo aluno permanece na escola ou em atividades escolares" (art. $4^{\circ}$, grifos meus).

A Lei $n^{\circ} 11.494 / 2007$ determina que, anualmente, sejam estabelecidas ponderações $^{5}$ (art.13, inciso I) aplicáveis às diferentes etapas, modalidades e tipos de estabelecimento de ensino da educação básica, as quais, quando mul-

3 O Fundeb, criado pela Emenda Constitucional $n^{\circ} 53 / 2006$ e regulamentado pela Lei $n^{\circ}$ 11.494/2007 e pelo Decreto $\mathrm{n}^{\circ}$ 6.253/2007, foi instituído no âmbito de cada Estado e do Distrito Federal, correspondendo assim a 27 (vinte e sete) Fundos: um para cada estado e um para o DF.

4 O Fundo de Manutenção e Desenvolvimento do Ensino Fundamental e de Valorização do Magistério foi instituído pela Emenda Constitucional $n^{\circ} 14 / 1996$, e regulamentado pela Lei ${ }^{\circ}$ 9.424/1996 e pelo Decreto $n^{\circ}$ 2.264/1997.

5 Essas ponderações são determinadas pela Comissão Intergovernamental de Financiamento para a Educação Básica de Qualidade, instituída no âmbito do Ministério da Educação (Lei 11.494/2007, art. $12, \S 2^{\circ}$ ). 
tiplicadas pelo valor anual mínimo por aluno definido nacionalmente (art. $4^{\circ}$, $\S 1^{\circ}$ e art. 15, inciso IV), resultam nos valores mínimos anuais do Fundeb por aluno integrante de cada uma dessas categorias. Partindo desse entendimento, a Tabela 1 - tendo por base: (1) as ponderações fixadas para os anos de 2007, 2009 e 2011; e (2) o valor anual mínimo por aluno definido nacionalmente para cada um desses anos $(\mathrm{R} \$ 947,24, \mathrm{R} \$ 1.221,34 \text { e } \mathrm{R} \$ 1.729,28)^{6}$ - apresenta os correspondentes valores anuais mínimos associados às diferentes etapas da educação básica pública em tempo integral.

TABELA 1 - FUNDEB - VALORES ANUAIS MÍNIMOS, SEGUNDO AS ETAPAS DA EDUCAÇÃO BÁSICA PÚBLICA EM TEMPO INTEGRAL, 2007/2009/2011

\begin{tabular}{l|c|c|c|c|c|c}
\hline \multirow{2}{*}{$\begin{array}{l}\text { Tempo } \\
\text { integral }\end{array}$} & \multicolumn{2}{|c|}{2007} & \multicolumn{2}{c|}{2009} & \multicolumn{2}{c}{2011} \\
\cline { 2 - 7 } & Ponderações $^{(1)}$ & $\begin{array}{c}\text { Valor } \\
\text { aluno }\end{array}$ & Ponderações $^{(2)}$ & $\begin{array}{c}\text { Valor } \\
\text { aluno }\end{array}$ & Ponderações $^{(3)}$ & $\begin{array}{c}\text { Valor } \\
\text { aluno }\end{array}$ \\
\hline Creche & 0,80 & 757,79 & 1,10 & $1.343,47$ & 1,20 & $2.075,13$ \\
\hline Pré Escola & 0,90 & 852,52 & 1,20 & $1.465,60$ & 1,30 & $2.248,06$ \\
\hline $\begin{array}{l}\text { Ensino } \\
\text { fundamental }\end{array}$ & 1,25 & $1.184,05$ & 1,25 & $1.562,67$ & 1,30 & $2.248,06$ \\
\hline $\begin{array}{l}\text { Ensino } \\
\text { Médio }\end{array}$ & 1,30 & $1.231,41$ & 1,30 & $1.587,74$ & 1,30 & $2.248,06$ \\
\hline
\end{tabular}

Nota: $\mathrm{O}$ cálculo do valor por aluno resulta da multiplicação do valor anual mínimo por aluno definido nacionalmente pela respectiva ponderação.

(1) Valores fixados na Lei $n^{\circ} 11.494 / 2007$ (art. 36). (2) Portaria MEC $n^{\circ} 932 / 2008$. (3) Portaria MEC $n^{\circ} 873 / 2010$.

A análise dos dados anteriores permite constatar que, se em 2007, as ponderações associadas às diferentes etapas, modalidades e tipos de estabelecimento de ensino apresentavam significativas diferenças entre si, em 2011, com exceção da creche ${ }^{7}$, todas passaram a ter o mesmo valor, 1,30, máximo permitido pela Lei n ${ }^{\circ} 11.494 / 2007$, que fixou sua variação no intervalo compreendido de 0,70 a $1,30\left(\right.$ art. $\left.10, \S 2^{\circ}\right)$. Esse fato - que se fez associar, entre outros, à necessidade de serem elevados os valores mínimos anuais por aluno para as diferentes etapas, modalidades e tipos de estabelecimentos de ensino da educação básica, incluindo as matrículas em tempo integral - acabou por resultar na ausência de diferenciação entre esses valores, os quais, em 2011, atingiram $\mathrm{R} \$ 2.248,06$ tanto para a pré-escola quanto para os ensinos

6 Valores fixados pelas Portarias Interministeriais $\mathrm{n}^{0} \mathbf{s}$ 1.030/2007, 788/2009 e 1.721/2011.

7 Em 2012, por meio da Portaria MEC n ${ }^{0} 1.322 / 2011$, a ponderação associada à creche pública em tempo integral também atingiu 1,30 (um inteiro e trinta centésimos). 
fundamental e médio.

Essa constatação aponta para uma possível retirada daquele sistema de balizas, de forma que as referidas ponderações possam ultrapassar o limite máximo disposto na legislação. Essa supressão se justifica pelo fato de as diferentes etapas, modalidades e tipos de estabelecimento de ensino apresentarem custos diferenciados e, sob essa perspectiva, necessitarem de recursos também distintos. Além disso, esses valores anuais por aluno ainda necessitam ser aumentados, pois, embora tenham passado por significativos avanços no período 2007-2011, ainda se encontram defasados em relação às reais necessidades da educação básica pública, e aqui se destaca, em tempo integral. Sendo assim, a exemplo do que vem sendo proposto por meio de emendas ao Projeto de Lei $\mathrm{n}^{\circ}$ 8.035/2010, que trata do Plano Nacional de Educação 2011-2020, observa-se a necessidade de alteração na Lei do Fundeb de forma a que essas ponderações tenham por referência custos reais. Mais especificamente, essas ponderações devem ter como base:

[...] as condições reais e os custos de cada etapa e modalidade de ensino, considerando, entre outros aspectos: a relação estudante/turma, a presença de infraestrutura e insumos adequados; qualificação dos profissionais de educação; presença de jornada em tempo integral dos estudantes (ANPED, 2011, p. 90).

A partir dessas considerações, é importante destacar que o avanço na qualidade da educação, amplamente evidenciada na legislação educacional brasileira, faz-se associar, entre outros, à implantação do custo aluno-qualidade como referência para seu financiamento. Segundo Carreira e Rezende Pinto (2007), a adoção do custo aluno-qualidade (CAQ) representa uma inversão na lógica do financiamento da educação e das demais políticas sociais no país, as quais, historicamente, vêm se submetendo à disponibilidade financeira imposta pelo ajuste fiscal. A lógica que prevalece no cálculo do valor médio gasto por aluno consiste na divisão dos recursos da vinculação constitucional, disposta no art. 212 da CF 1988, pelo número de matrículas, recursos estes na maioria das vezes escassos, uma vez que estão submetidos às flutuações da economia e às políticas fiscais postas em prática pelos governos.

Ainda de acordo com Carreira e Rezende Pinto (2007), "o CAQ trilha outro caminho ao nascer da pergunta: qual é o investimento por aluno que o País precisa fazer para que haja a ampliação do acesso e a melhoria da qualidade da educação [...]?” (p. 13). Sob essa perspectiva, apresentam uma 
proposta de Custo Aluno-Qualidade inicial (CAQi), numa clara indicação de que se constitui em um ponto de partida, "o primeiro passo para uma escola pública de qualidade" (p. 15). Após a apresentação dos resultados de seus estudos, os autores evidenciam que são quatro os fatores que exercem maior influência no cálculo do CAQi: (1) o tamanho do estabelecimento de ensino; (2) a jornada escolar; (3) a relação alunos/turma ou alunos/professor; (4) a remuneração dos profissionais da educação, em especial dos docentes. $\mathrm{Na}$ sequência, Carreira e Rezende Pinto (2007) apresentam os valores obtidos para CAQi para as diferentes etapas da educação básica e evidenciam a necessidade de serem determinados valores para grupos específicos - educação inclusiva, indígena, profissional, do campo e quilombola. No que tange ao tempo integral, o estudo já deu um primeiro passo ao calcular o CAQi para as creches em tempo integral, considerando a jornada de 10 horas diárias. No livro os autores apresentam que, para o ano de 2009, o CAQi para creches em tempo integral deveria corresponder a $\mathrm{R} \$ 5.600,00$, resultado este significativamente superior ao valor anual mínimo por aluno definido nacionalmente para o Fundeb, para o mesmo ano, qual seja, R\$1.343,47. Esse fato revela, entre outros, a importância de continuarem a serem desenvolvidos estudos vinculados ao Custo Aluno-Qualidade, associados ao tempo integral nas demais etapas da educação básica pública, que sejam utilizados como parâmetros para o Fundeb.

No âmbito do Fundo é importante evidenciar que, caso o estado não atinja o valor anual mínimo fixado nacionalmente para investimentos por estudante da rede pública, a União complementará seus recursos, dentro do estabelecido na legislação que envolve o Fundeb (Lei 11.494/2007, art. $4^{\circ}$ ). Tendo por base essa determinação legal, a Tabela 2, que tem por objetivo possibilitar subsídios para a análise sobre a complementação da União aos fundos estaduais, apresenta os valores realizados nas etapas da educação básica pública em tempo integral, durante o ano de 2011, por dois estados brasileiros com comportamentos distintos em relação ao Fundeb: (1) a Bahia, que, por meio do Fundo, recebeu recursos adicionais da União de forma a atingir os valores mínimos por aluno matriculado em cada uma das etapas da educação básica e (2) São Paulo, que não recebeu complementação. 
TABELA 2 - FUNDEB - VALOR POR ALUNO NA EDUCAÇÃO BÁSICA PÚBLICA EM TEMPO INTEGRAL NOS ESTADOS DA BAHIA E DE SÃO PAULO, 2011

\begin{tabular}{|c|c|c|c|c|c|}
\hline \multirow[t]{2}{*}{ Estados } & \multicolumn{4}{|c|}{$\begin{array}{l}\text { Valor anual por aluno na educação básica } \\
\text { pública em tempo integral (R\$) }\end{array}$} & \multirow{2}{*}{$\begin{array}{l}\text { Complementação } \\
\text { da União }\left(^{*}\right) \\
\text { (R\$ mil) }\end{array}$} \\
\hline & Creche & Pré-escola & $\begin{array}{c}\text { Ensino } \\
\text { Fundamental }\end{array}$ & Ensino Médio & \\
\hline Bahia & $2.075,13$ & $2.248,06$ & $2.248,06$ & $2.248,06$ & $1.674 .502,70$ \\
\hline São Paulo & $3.168,45$ & $3.432,49$ & $3.432,49$ & $3.432,49$ & - \\
\hline
\end{tabular}

FONTE: Dados oriundos do Anexo I da Portaria Interministerial $n^{\circ} 1.721 / 2011$

(*) Este valor está associado ao financiamento de todas as diferentes etapas, modalidades e tipos de estabelecimento de ensino, independentemente da extensão da jornada escolar.

A análise conjunta das Tabelas 1 e 2 evidencia que, em 2011, a complementação da União (aproximadamente R $\$ 1,7$ bilhões) possibilitou que, no âmbito dos recursos do Fundeb, o estado da Bahia elevasse os valores por aluno que seriam praticados no financiamento da sua educação básica, incluindo as matrículas em tempo integral, de forma a que atingissem valores anuais mínimos. Essa constatação pode ser estendida para todos os estados que recebem complementação federal associada ao Fundeb.

Tomando por referência os dados da Tabela 2 é possivel observar ainda que o valor anual por aluno matriculado na educação básica pública em tempo integral de São Paulo, que nunca recebeu complementação da União por meio do Fundeb, mantém-se significativamente maior (53\%) do que o realizado na Bahia, mesmo após este estado ter recebido recursos adicionais do governo federal. De modo geral, é possível afirmar que o Fundo eleva o patamar do investimento por aluno no âmbito dos estados que recebem complementação da União, diminuindo as diferenças associadas ao financiamento da educação básica pública entre os estados da Federação, sem, todavia, combatê-las de forma contundente.

Ainda em relação ao Fundeb, convém apresentar que os governos estaduais e municipais, de acordo com as determinações da Lei ${ }^{\circ} 11.494 / 2007$ (art. $9^{\circ}, \S 1^{\circ}$ ), só poderão receber recursos associados às matrículas referentes aos seus respectivos âmbitos de atuação prioritária, conforme determinação dos $\S \S 2^{\circ}$ e $3^{\circ}$ do art. 211 da CF 1988. Detalhando, no que tange ao Fundeb, (1) os municípios só podem receber recursos associados às suas matrículas na educação infantil e no ensino fundamental; (2) já os estados, referente às matrículas sob sua responsabilidade nos ensinos fundamental e médio - e nas modalidades associadas às correspondentes etapas de ensino, cobertas pelo Fundo, incluindo o tempo integral. 
Tendo por referência a constatação de que o Fundeb se constitui na principal política federal de financiamento da educação básica pública em tempo integral, convém destacar a significativa importância que o Programa Mais Educação (PME) vem conquistando no contexto desse financiamento.

Instituído pela Portaria Interministerial $n^{\circ} 17 / 2007$ e pelo Decreto $n^{\circ}$ 7.083/2010, o Programa Mais Educação, assim como o Fundeb, foi criado no âmbito do Plano de Desenvolvimento da Educação (PDE). Concebido como uma estratégia do governo federal que visa "induzir a ampliação da jornada escolar e a organização curricular, na perspectiva da educação integral" (MEC, 2011a, p. 01), o Programa tem por finalidade "contribuir para a melhoria da aprendizagem por meio da ampliação do tempo de permanência de crianças, adolescentes e jovens matriculados em escola pública, mediante oferta de educação básica em tempo integral" (Decreto 7.083/2010, art. $1^{\circ}$ ).

No que tange ao financiamento, é importante evidenciar que o PME - que tem como área de atuação especialmente as capitais, as regiões metropolitanas, os territórios de vulnerabilidade social/áreas prioritárias da ação socioeducativa e as escolas com baixo Índice de Desenvolvimento da Educação (IDEB) (FARIA, 2011) - é operacionalizado pela Secretaria de Educação Básica (SEB) ${ }^{8}$, por meio do Programa Dinheiro Direto na Escola (PDDE), do Fundo Nacional de Desenvolvimento da Educação (FNDE). Nesse sentido, as escolas públicas que possuem alunos matriculados no ensino fundamental e médio, selecionadas pela SEB/MEC e que aderiram ao Programa, recebem os recursos financeiros correspondentes à implementação do PME por intermédio de suas Unidades Executoras Próprias (UEx) (Resolução FNDE nº 20/2011).

Os recursos do PME devem ser destinados para despesas de custeio e/ou capital, conforme disposto no Quadro 1:

8 Até o ano de 2010, o PME esteve sob a responsabilidade da Secretaria de Educação Continuada, Alfabetização e Diversidade (Secad /MEC), ocasião em que foi transferido para a Secretaria de Educação Básica (SEB/MEC). 
QUADRO 1 - DESTINAÇÃO DOS RECURSOS DO PROGRAMA MAIS EDUCAÇÃO, SEGUNDO A CATEGORIA ECONÔMICA

\begin{tabular}{|c|l|}
\hline Categorias Econômicas & \multicolumn{1}{|c|}{ Destinação } \\
\hline Custeio & $\begin{array}{l}\text { Ressarcimento de despesas de ali- } \\
\text { mentação e transporte dos monitores } \\
\text { responsáveis pelo desenvolvimento das } \\
\text { atividades do PME. } \\
\text { • Aquisição de materiais de consumo } \\
\text { ou contratação de serviços. }\end{array}$ \\
\hline Capital & - Aquisição de materiais permanentes. \\
\hline Custeio e/ou capital & $\begin{array}{l}\text { Aquisição de kits de materiais e/ou } \\
\text { serviços definidos no âmbito do Programa, } \\
\text { de acordo com as atividades selecionadas } \\
\text { por cada escola. }\end{array}$ \\
\hline
\end{tabular}

FONTE: Quadro elaborado a partir de informações contidas no Manual do PDDE/Educação Integral/2011

Tendo em vista as possibilidades de aplicação de recursos no âmbito do Programa Mais Educação, a Tabela 3, que tem por objetivo subsidiar a reflexão sobre a evolução do atendimento, bem como do investimento federal no Programa, revela que ambas as categorias apresentaram significativo aumento, embora o investimento médio por aluno, afora pequenas oscilações, tenha se mantido praticamente inalterado no período analisado.

TABELA 3 - NÚMERO DE ESTABELECIMENTOS DE ENSINO, ALUNOS E VOLUME DE RECURSOS DESTINADOS AO PROGRAMA MAIS EDUCAÇÃO - 2008-2011

\begin{tabular}{l|c|c|c|c}
\hline \multirow{2}{*}{} & \multicolumn{4}{|c}{ Anos } \\
\cline { 2 - 5 } & 2008 & 2009 & 2010 & 2011 \\
\hline $\mathrm{N}^{\circ}$ Escolas & 1380 & 5.006 & 10.026 & 14.995 \\
\hline $\mathrm{N}^{\circ}$ Alunos & 317.874 & 1.181 .440 & 2.551 .723 & 3.367 .703 \\
\hline Recurso (R\$) & $89.978 .405,32$ & $276.730 .036,52$ & $615.290 .662,48$ & $986.989 .913,10$ \\
\hline $\begin{array}{l}\text { Investimento médio } \\
\text { por aluno/ano }\end{array}$ & 283,06 & 234,23 & 273,25 & 293,07 \\
\hline
\end{tabular}

FONTE: Nota Técnica nº 61/2011-DICEI/SEB/MEC

Embora, no período de quatro anos, tenha ocorrido importante avanço associado ao atendimento e ao financiamento do Programa, quando comparamos o valor médio por aluno/ano realizado pelo Fundeb (dados dispostos na Tabela 1) com o realizado pelo $\mathrm{PME}^{9}$, verificamos que este é significativamente inferior àquele.

9 O PME historicamente vem atendendo ao ensino fundamental, tendo iniciado, em 2011, o atendimento ao ensino médio. 
A esse respeito convém destacar dois pontos. Primeiro, o financiamento da educação básica pública em tempo integral tem sua garantia associada ao Fundeb, que destina recursos para todas as matrículas com extensão da jornada escolar correspondente a, no mínimo, sete horas diárias, recursos estes que podem apresentar um percentual até $60 \%{ }^{10}$ superior aos que são realizados nas diferentes etapas, modalidades e tipos de estabelecimentos de ensino da educação básica. Segundo, os recursos do Mais Educação, tendo por referência o fato de que o Programa objetiva se constituir estratégia indutora de políticas municipais e estaduais de educação em tempo integral com vistas à Educação Integral, devem ser computados como um aporte adicional ao financiamento das matrículas em tempo integral e, como tal, devem ser contabilizados para além dos recursos do Fundo. Ou seja, o financiamento do PME, entre outras possibilidades, pode contar com duas fontes: a do próprio Programa (PDDE/ Educação Integral) e a do Fundeb, desde que suas matrículas atendam ao disposto no art. $4^{\circ}$ do Decreto $n^{\circ} 6.253 / 2007$.

A Tabela 4, que apresenta informações sobre o número de matrículas em tempo integral, bem como sobre o número de alunos no Programa Mais Educação, associados ao ensino fundamental, revela diferenças entre esses resultados.

TABELA 4 - BRASIL - MATRÍCULAS EM TEMPO INTEGRAL E NÚMERO DE ALUNOS NO PROGRAMA MAIS EDUCAÇÃO, 2009 E 2010

\begin{tabular}{|c|c|c|}
\hline Anos & Tempo integral & PME \\
\hline 2009 & 945.044 & 1.181 .440 \\
\hline 2010 & 1.203 .905 & 2.251 .723 \\
\hline
\end{tabular}

FONTE: INEP/MEC (matrículas com tempo integral) e SEB/MEC (número de alunos integrantes do PME).

Uma leitura rápida da tabela poderia conduzir ao entendimento de que, para os anos observados, o total de matrículas em tempo integral, levantado pelo INEP, deveria ser igual ao número de alunos registrados no Programa Mais Educação. A esse respeito, vale ressaltar que inicialmente o Mais Educação estava normatizado pela Portaria Interministerial $n^{\circ} 17 / 2007$, a qual não apresentava uma definição associada ao tempo integral. Esta lacuna possibilitou que, durante os anos iniciais de implantação do PME, as escolas se organizassem de acordo com suas possibilidades e limitações. Sendo assim, algumas delas optaram por incluir um maior número de alunos no Programa, dividindo-os em grupos que permaneciam sob sua responsabilidade por sete horas ou mais apenas em dias

10 Conforme evidenciado anteriormente, as ponderações estão compreendidas no intervalo de 07 a 1,3 . 
específicos da semana, isto é, o tempo integral, diferentemente do que dispõe o Fundeb, não estava associado a todos os dias da semana.

Ultrapassado o período inicial de divulgação e implantação do Mais Educação no país, por meio do Decreto ${ }^{\circ} 7.083 / 2010$, a educação básica em tempo integral, no âmbito deste Programa, passou a corresponder "a jornada escolar com duração igual ou superior a sete horas diárias, durante todo o período letivo, compreendendo o tempo total em que o aluno permanece na escola ou em atividades escolares em outros espaços educacionais" $\left(\operatorname{art.} 1^{\circ}, \S 1^{\circ}\right)$. Assim, ao apresentar uma definição para educação básica em tempo integral semelhante à do Fundeb, o Programa Mais Educação, além de possibilitar o direcionamento de recursos deste Fundo para todas as suas matrículas, contribuiu para a reflexão sobre a importância de serem estabelecidas estratégias de financiamento com vistas à construção, à manutenção e ao fortalecimento da política de educação (em tempo) integral por parte de estados e municípios.

Na prática, tomando como exemplo os dados da Tabela 4, atualmente não é desejável que as estatísticas continuem a evidenciar que o número de alunos no PME é maior do que o número de matrículas em tempo integral, pois essa diferença corresponde ao total de matrículas que não se adéqua à definição de educação básica em tempo integral, disposta nos Decretos 6.253/2007 e $7.083 / 2010$, matrículas estas que, no contexto atual, não fazem jus ao recebimento de recursos nem do Fundeb nem do PME.

Convém destacar ainda que, ambos - Fundeb e PME - têm seus depósitos realizados em contas únicas e específicas para os fins a que se destinam (Lei 11.494/2007, art. 17 e Resolução ${ }^{\circ}$ 20/2011, art. $2^{\circ}$ ), fato que possibilita melhores condições de acompanhamento e controle por parte da comunidade, dos conselhos específicos e dos Tribunais de Contas. Todavia, ao mesmo tempo em que os recursos do PME são creditados na conta corrente da Unidade Executora Própria (UEx) de cada escola integrante do Programa, os do Fundeb são depositados em contas específicas dos governos estaduais, do Distrito Federal e dos municípios. A esse respeito, observa-se que não há uma orientação legal, no âmbito do Fundeb, que determine que os recursos (ou parte deles) associados à oferta em tempo integral (ou não) devam ser redistribuídos para as escolas que disponibilizam essas matrículas. Ao contrário, a Lei no 11.494/2007 apresenta que os recursos do Fundo, inclusive aqueles oriundos de complementação da União, "poderão ser aplicados pelos Estados e Municípios indistintamente entre etapas, modalidades e tipos de estabelecimento de ensino da educação básica nos seus respectivos âmbitos de atuação prioritária" (art. $21, \S 1^{\circ}$ ).

Por fim, tendo por referência essas constatações, evidencia-se a importância de estados e municípios que recebem recursos associados ao tempo integral na sua conta Fundeb estabelecerem estratégias de transferência direta de parte deles (alguns já o fazem) para os estabelecimentos de ensino que vêm empenhando 
esforços com vistas a disponibilizarem matrículas com, no mínimo, sete horas diárias. Esta orientação parte do entendimento de que a descentralização financeira se constitui decisão estratégica de estados e municípios que objetivam construir e/ou fortalecer sua política de educação em tempo integral.

\section{Algumas considerações}

O texto constitucional, com redação dada pela Emenda Constitucional 14/1996, redefiniu as funções da União no contexto da educação nacional e de seu financiamento. A partir da Emenda 14, a União, no que tange às instâncias subnacionais, passou a desempenhar função de redistribuição e/ou suplementação de recursos. O Fundeb e o Programa Mais Educação constituem-se em exemplos associados a essa nova perspectiva. Além disso, a União passou a ter a responsabilidade de prestar assistência técnica e financeira aos estados, Distrito Federal e municípios, de forma a garantir "a equalização de oportunidades educacionais e padrão mínimo de qualidade de ensino" (art. $211, \S 1^{\circ}$ ). Mais especificamente, a União, com vistas a ir ao encontro de um projeto educacional para o país, disposto no Plano Nacional de Educação, passou a exercer, entre outras, a função indutora no que tange à implantação e desenvolvimento de ações voltadas para o combate às desigualdades e ao avanço da qualidade em educação.

Essa nova orientação legal expõe a temporalidade de grande parte das ações do MEC, planejadas para um determinado período de tempo, durante o qual o Ministério presta assistência técnica e financeira aos estados, DF e municípios que aderiram a alguma(s) de suas ações/Programas, sendo que, durante este período, as instâncias subnacionais devem desenvolver condições para, após o afastamento do MEC, poderem dar continuidade às referidas ações/Programas, estes, desde o início de sua implantação, (re)configurados de forma a ir ao encontro do seu projeto educacional. A partir do exposto, é possível afirmar que a reorientação do papel da União no contexto da Emenda 14 possibilita subsídios para que estados, DF e municípios reflitam sobre a importância do seu próprio papel na continuidade (ou não) de ações e/ou Programas, inicialmente desenvolvidos com o apoio do MEC, e, posteriormente, sob sua total responsabilidade.

Finalizando, se por um lado, graças, entre outros aspectos, à implementação de Programas, o Brasil deu a largada para lançar sua educação a patamares mínimos desejáveis, por outro, continua a necessitar de uma política consistente e sustentável, acima de interesses partidários momentâneos, que garanta o tão valorizado e necessário "padrão de qualidade" na educação. É preciso também que a proposta de uma política de Estado para a educação, amplamente destacada na Conferência Nacional de Educação (Conae), se concretize. Quem sabe 
assim o Brasil terá melhores condições de concorrer e garantir o tão almejado espaço entre as grandes potências do planeta?

\section{REFERÊNCIAS}

ASSOCIAÇÃO NACIONAL DE PÓS-GRADUAÇÃO E PESQUISA EM EDUCAÇÃO (ANPED). Por um Plano Nacional de Educação (2011-2020) como política de Estado. Rio de Janeiro, 2011.

BRASIL. Resolução $n^{\circ} 20$, de 06 maio de 2011. Dispõe sobre a destinação de recursos financeiros nos moldes e sob a égide da Resolução ${ }^{\circ}$ 17, de 19 de abril de 2011, as escolas públicas municipais, estaduais e do Distrito Federal, com vistas a assegurar a realização de atividades de Educação Integral, de forma a compor a jornada escolar de, no mínimo, sete horas diárias. Diário Oficial da União, Brasília, DF, 2011.

. Portaria Interministerial $\mathrm{n}^{\circ} 1.721$, de 07 de novembro de 2011. Retifica os parâmetros operacionais do Fundo de Manutenção e Desenvolvimento da Educação Básica e de Valorização dos Profissionais da Educação - FUNDEB, para o ano de 2011. Diário Oficial da União, Brasília, DF, 08 dez. 2011.

. Decreto ${ }^{\circ} .7 .083$, de 27 de janeiro de 2010. Dispõe sobre o Programa Mais Educação. Diário Oficial da União, Brasília, DF, 27 jan. 2010.

. Decreto $\mathrm{n}^{\circ}$. 6.253, de 13 de novembro de 2007. Dispõe sobre o Fundo de Manutenção e Desenvolvimento da Educação Básica e de Valorização dos Profissionais da Educação - FUNDEB, regulamenta a Lei no 11.494, de 20 de junho de 2007, e dá outras providências. Diário Oficial da União, Brasília, DF, 14 nov. 2007.

. Lei n ${ }^{\circ} 11.494$, de 20 de junho de 2007. Regulamenta o Fundo de Manutenção e Desenvolvimento da Educação Básica e de Valorização dos Profissionais da Educação - FUNDEB. Diário Oficial da União, Brasília, DF, 21 jun. 2007.

. Lei no 10.172 , de 09 de janeiro de 2011. Aprova o Plano Nacional de Educação e dá outras providências. Diário Oficial da União, Brasília, DF, 10 jan. 2001.

. Lei $\mathrm{n}^{\circ}$ 9.394, de 20 de dezembro de1996. Estabelece as diretrizes e bases da educação nacional. Diário Oficial da União, Brasília, DF, 23 dez. 1996.

. Constituição Federal de 1988. Brasília: Senado Federal, 1988.

CARREIRA, D.; REZENDE PINTO, J. M. Custo aluno-qualidade inicial: rumo à educação pública de qualidade no Brasil. São Paulo: Global; Campanha Nacional pelo Direito à Educação, 2007. 
FARIA, T. C. F. Reflexões sobre a implantação do Programa Mais Educação na rede municipal de ensino de Natal, RN. Quipus: Revista Científica das Escolas de Comunicação e Artes e Educação, UnP. Natal: Edunp, Ano 1, n. 1, dez. 2011 / maio 2012.

MENEZES, Janaina S. S. Educação integral \& tempo integral na educação básica. In: COELHO, L. M. C. C. (Org.). Educação integral em tempo integral: estudos e experiências em processo. Petrópolis, RJ: DP; Rio de Janeiro: FAPERJ, 2009.

MINISTÉRIO DA EDUCAÇÃO (MEC). Secretaria de Educação Básica. Diretoria de Currículo e Educação Integral. Manual da educação integral em jornada ampliada para obtenção de apoio financeiro por meio do Programa Dinheiro Direto na Escola - PDDE/Educação Integral, no exercício de 2011. Brasília, 2011a.

Nota Técnica nº. 61/2011-DICEI/SEB/MEC. Brasília, 2011b.

RIOS, Terezinha Azeredo. Compreender e ensinar: por uma docência de melhor qualidade. São Paulo: Cortez, 2006.

Texto recebido em 27 de março de 2012.

Texto aprovado em 29 de abril de 2012. 